\title{
07.2
}

\section{Свойства резистивных структур на основе полиморфных фаз оксида галлия}

\author{
(c) В.М. Калыгина ${ }^{1}$, В.И. Николаев ${ }^{2}$, А.В. Алмаев ${ }^{1}$, А.В. Цымбалов ${ }^{1}$, Ю.С. Петрова ${ }^{1}$, И.А. Печников ${ }^{3}$, \\ П.Н. Бутенко 2,3 \\ ${ }^{1}$ Национальный исследовательский Томский государственный университет, Томск, Россия \\ ${ }^{2}$ ООО „Совершенные кристаллы“, Санкт-Петербург, Россия \\ ${ }^{3}$ Физико-технический институт им. А.Ф. Иофрфе РАН, Санкт-Петербург, Россия \\ E-mail: kalygina@ngs.ru
}

Поступило в Редакцию 16 апреля 2020г.

В окончательной редакции 30 мая 2020г.

Принято к публикации 30 мая 2020 г.

\begin{abstract}
Рассмотрено влияние УФ-излучения и сильного электрического поля на вольт-амперные характеристики резистивных структур на основе полиморфных пленок оксида галлия $\left(\mathrm{Ga}_{2} \mathrm{O}_{3}\right)$. Пленки $\mathrm{Ga}_{2} \mathrm{O}_{3}$ осаждались методом хлоридной газофазной эпитаксии (HVPE) на гладкие и структурированные сапфировые подложки с базисной ориентацией (0001). На гладких подложках растут пленки $\alpha-\mathrm{Ga}_{2} \mathrm{O}_{3}$, а на структурированных пленки оксида галлия, содержащие $\alpha$ - и $\varepsilon$-фазы. В структурах металл/ $\mathrm{Ga}_{2} \mathrm{O}_{3} /$ металл на основе двухфазных пленок обнаружен эффект переключения. При воздействии излучения с $\lambda=254 \mathrm{~nm}$ и сильного электрического поля структуры переходят из состояния с низким сопротивлением в состояние с высоким сопротивлением.
\end{abstract}

Ключевые слова: оксид галлия, пленки, НVPE, полиморфизм, ультрафиолет, солнечно-слепые структуры.

DOI: 10.21883/PJTF.2020.17.49891.18341

Оксид галлия является бинарным полупроводниковым соединением, которое может кристаллизоваться в пяти модификациях: $\alpha, \beta, \gamma, \delta$ и $\varepsilon[1-3]$. Благодаря своим физико-химическим свойствам этот широкозонный полупроводник представляет практический интерес для создания солнечно-слепых детекторов УФ-диапазона, высоковольтных приборов, газовых сенсоров, прозрачных электродов и т.д. [4]. На данный момент наиболее изученным является $\beta-\mathrm{Ga}_{2} \mathrm{O}_{3}\left(E_{g} \sim 4.8 \mathrm{eV}\right)$ благодаря его высокой термической и химической стабильности [5-7]. $\beta-\mathrm{Ga}_{2} \mathrm{O}_{3}$ обладает моноклинной решеткой, параметры которой имеют большое рассогласование с другими полупроводниковыми кристаллами, такими как $\mathrm{Al}_{2} \mathrm{O}_{3}, \mathrm{Si}$, $\mathrm{SiC}$ и др. Это осложняет рост высококачественных слоев $\beta-\mathrm{Ga}_{2} \mathrm{O}_{3}$, включая эпитаксиальный, на этих подложках [8]. Политип $\alpha-\mathrm{Ga}_{2} \mathrm{O}_{3}$, имеющий структуру корунда и характеризующийся небольшой разницей в постоянных кристаллической решетки с сапфиром $(\Delta c / c=3.3 \%$ и $\Delta a / a=4.5 \%)$, кристаллизуется на его поверхности в слоях высокого структурного совершенства [9]. Отметим, что $\alpha-\mathrm{Ga}_{2} \mathrm{O}_{3}$ обладает наибольшим значением ширины запрещенной зоны $(5.1-5.3 \mathrm{eV})$ [10], что позволяет рассматривать его в качестве перспективы для создания солнечно-слепых детекторов в диапазоне глубокого УФ.

Эпитаксиальные пленки оксида галлия $n$-типа проводимости, легированные оловом, выращивались методом хлоридной газофазной эпитаксии (HVPE) в реакторе ООО „Совершенные кристаллы“. Для осаждения использовались гладкие и структурированные сапфировые подложки (PSS) с ориентацией (0001). В одном ростовом процессе на гладких подложках были полу- чены слои чистой фазы $\alpha-\mathrm{Ga}_{2} \mathrm{O}_{3}$, а на профилированных - двухфазные слои с колончатыми структурами $\alpha-\mathrm{Ga}_{2} \mathrm{O}_{3} / \varepsilon-\mathrm{Ga}_{2} \mathrm{O}_{3}$ [11,12]. Цель настоящей работы изучить особенности электрических и фотоэлектрических характеристик тонких слоев оксида галлия в зависимости от структуры подложки.

Для измерения электрических характеристик на поверхности слоев оксида галлия посредством магнетронного напыления через шаблон формировались платиновые контакты, расстояние между которыми $d=1.85 \mathrm{~mm}$. Затем пластины разрезались на отдельные чипы размером $1.85 \times 1 \mathrm{~mm}$. Полученные образцы распаивали в корпусы марки ТО-8.

Темновые вольт-амперные и фотоэлектрические характеристики измерялись при комнатной температуре с помощью источника-измерителя Keithley 2611. В качестве источника УФ-излучения использовались лампа VL-6 с фильтром, обеспечивающая максимум излучения при $\lambda=254 \mathrm{~nm}$, и эксимерная $\mathrm{KrCl}$-лампа с $\lambda=222$ $\mathrm{nm}$. Структуры, сформированные на гладких подложках, имели темновые токи $\left(I_{D}\right)$, не превышающие $10-70 \mathrm{pA}$ при напряжениях от 0 до $\pm 200 \mathrm{~V}$. Значения тока при воздействии излучения $\left(I_{L}\right)$ с $\lambda=254 \mathrm{~nm}$ практически не отличались от темновых, в то время как при облучении с $\lambda=222 \mathrm{~nm}$ наблюдалось увеличение электропроводности образцов (рис. $1, a)$.

Одной из причин отсутствия отклика образцов на излучение с $\lambda=254 \mathrm{~nm}$ может быть несколько бо́льшая ширина запрещенной зоны оксидной пленки, выращенной на гладкой сапфировой подложке. При использовании источника с $\lambda=222 \mathrm{~nm}$ квант энергии излучения 

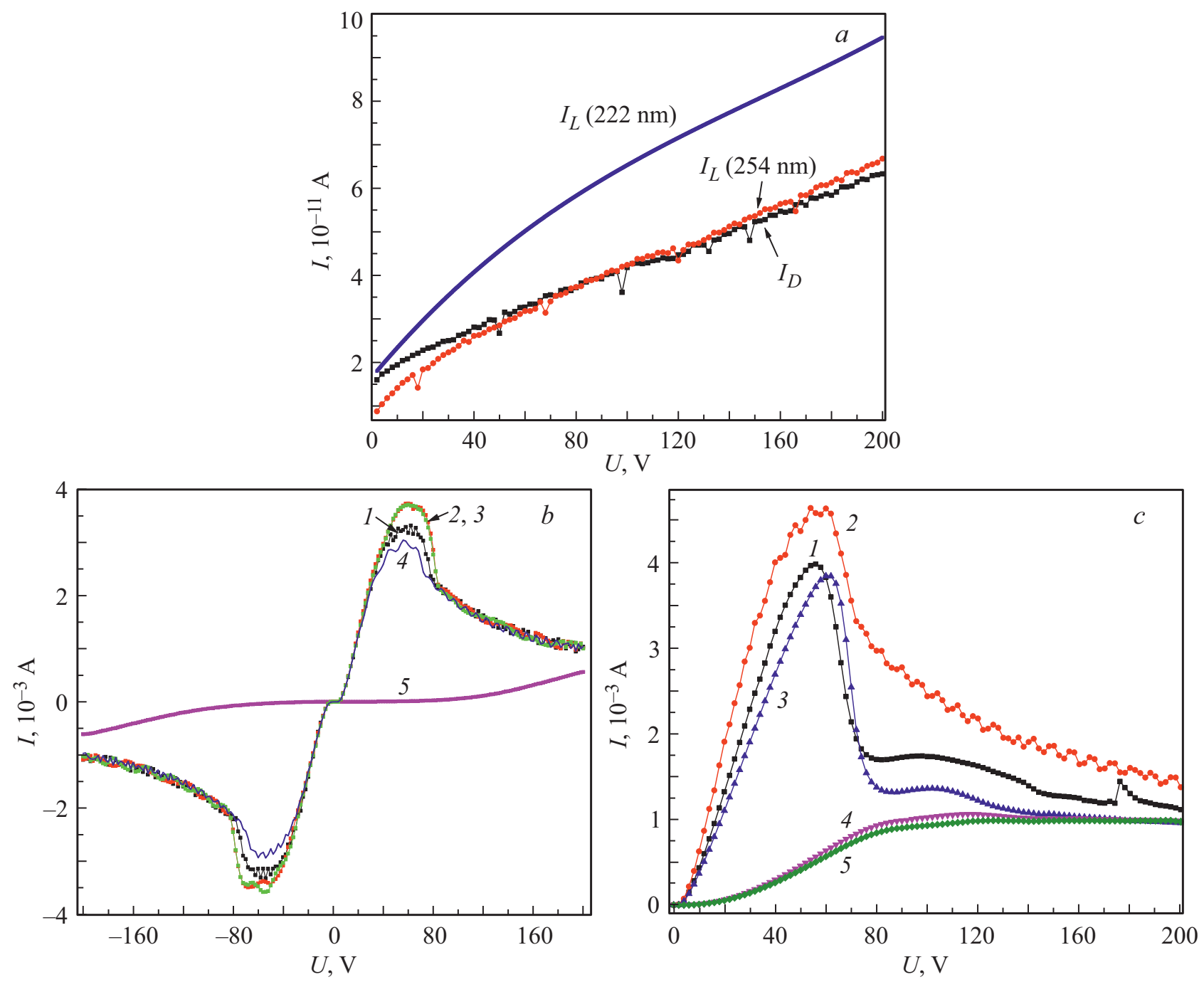

Рис. 1. $a-$ вольт-амперные характеристики образца $\alpha-\mathrm{Ga}_{2} \mathrm{O}_{3}: \mathrm{Sn}$, полученного на гладкой сапфировой подложке: темновой ток $\left(I_{D}\right)$ и токи при воздействии УФ $(\lambda=254$ и $222 \mathrm{~nm})\left(I_{L}\right) . b-$ вольт-амперные характеристики двухфазного образца $\alpha-\varepsilon-\mathrm{Ga}_{2} \mathrm{O}_{3}: \mathrm{Sn}$ полученного на структурированной сапфировой подложке в интервале $-200 \leqslant U \leqslant+200 \mathrm{~V}: 1-$ исходная темновая ВАХ; $2,3-$ ВАХ при воздействии УФ; 4 - темновая ВАХ после выключения УФ; 5 - темновая ВАХ после воздействия сильного

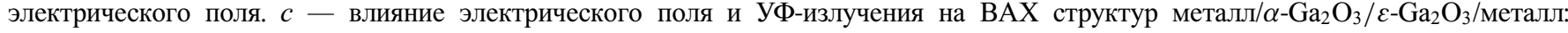
1 - исходная темновая ВАХ; 2 - ВАХ при воздействии УФ; 3 - темновая ВАХ после выключения УФ; 4, 5 - темновые ВАХ после воздействия сильного электрического поля.

равен $5.06 \mathrm{eV}$ и близок к краю собственного поглощения, а при $\lambda=254 \mathrm{~nm}$ составляет $h v=4.88 \mathrm{eV}$, что меньше указанного выше значения $E_{g}$ для $\alpha-\mathrm{Ga}_{2} \mathrm{O}_{3}$.

Вольт-амперные характеристики (BAX) слоев на структурированных подложках симметричны относительно полярности напряжения $U$ в интервале $-200 \leqslant U \leqslant+200 \mathrm{~V}$ (рис. $1, b$ ). Исходные темновые ВАХ (до воздействия сильных электрических полей и УФ-излучения) имеют вид кривых с максимумом (рис. $1, b, c$, кривые 1 ). При подаче смещения на образцы темновой ток $I_{D}$ увеличивается и достигает максимального значения при $U_{m}=50-70 \mathrm{~V}$. Дальнейшее повышение напряжения приводит к резкому снижению $I_{D}$, и при напряжениях выше 80-100 V наблюдается сравнительно слабая зависимость темнового тока от напряжения. Во время действия источника с $\lambda=254 \mathrm{~nm}$ зависимость $I$ от $U$ по-прежнему имеет выраженный максимум, и ток при освещении $I_{L}$ незначительно превосходит темновой $I_{D}$ (рис. 1, $c$, кривые 1,2). После выключения УФ повышенные значения $I_{D}$ сохраняются в течение нескольких суток, если на образцы не подавать высокое напряжение (рис. 1, c, кривая 3). Однако если на образец подать смещение, примерно равное $100-200 \mathrm{~V}$, то характер темновой вольт-амперной характеристики резко изменяется: на кривой зависимости $I$ от $U$ исчезает максимум и темновой ток при низких напряжениях снижается на два порядка (рис. 1,c, кривые 4,5); ВАХ описываются монотонной зависимостью тока от напряжения; образец переходит в состояние с высоким сопротивлением (BC). На рис. 2, a приведены темновые ВАХ одного 

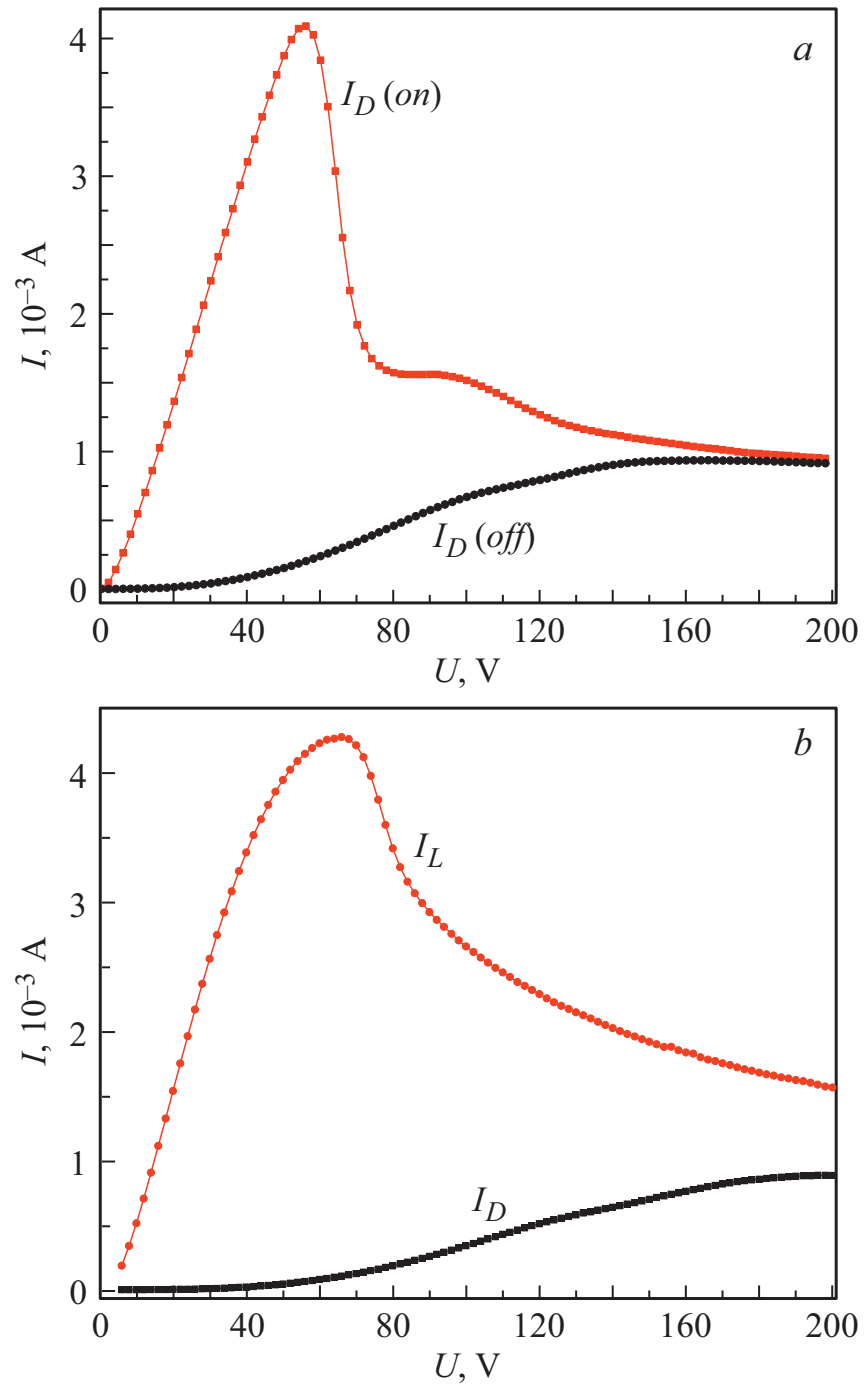

Рис. 2. $a-$ эффект переключения в структурах металл/ $\alpha-\mathrm{Ga}_{2} \mathrm{O}_{3} / \varepsilon-\mathrm{Ga}_{2} \mathrm{O}_{3} /$ металл: on - состояние с низким сопротивлением, off - состояние с высоким сопротивлением. $b-$ влияние УФ-излучения на ВАХ после переключения образца в состояние с высоким сопротивлением.

из образцов до и после воздействия УФ-излучения и сильного электрического поля, показывающие эффект переключения образца из состояния с низким сопротивлением в состояние с ВС. После переключения структуры обнаруживают высокую чувствительность к УФ-излучению в интервале $-60 \leqslant U \leqslant+60 \mathrm{~V}$ (рис. $2, b$ ).

Большие начальные значения темновых токов в образцах на PSS могут быть связаны с присутствием двух политипов оксида галлия, где в случае полярной фазы $\varepsilon-\mathrm{Ga}_{2} \mathrm{O}_{3}$ возможно образование областей двумерного электронного газа (2DEG) [13]. $\varepsilon-\mathrm{Ga}_{2} \mathrm{O}_{3}$ имеет сегнетоэлектрические свойства [14], вектор спонтанной поляризации ориентирован вдоль направления оси роста [0001] $($ ось $c)$. Под действием сильного электрического поля поляризация может изменять направление на противоположное. Снижение тока при $U>U_{m}$, вероятно, вызвано нарушением условий существования 2DEG, возможно за счет изменения вектора спонтанной поляризации $\mathbf{P}_{s p}$. В результате структура переходит из проводящего состояния в состояние с высоким сопротивлением.

Чувствительность к УФ-излучению с $\lambda=254$ nm двухфазных слоев на PSS-подложке, вероятно, обусловлена тем, что $\varepsilon$-фаза $\mathrm{Ga}_{2} \mathrm{O}_{3}$ имеет меньшую ширину запрещенной зоны по сравнению с $\alpha$-фазой. Подводя итог, можно сделать следующие выводы.

1. Электрические и фотоэлектрические характеристики эпитаксиальных пленок $\mathrm{Ga}_{2} \mathrm{O}_{3}$, выращенных HVPЕ-методом, зависят от их структуры, которая в свою очередь определяется профилем сапфировой подложки.

2. В двухфазных образцах с $\alpha-\mathrm{Ga}_{2} \mathrm{O}_{3} / \mathcal{\varepsilon}-\mathrm{Ga}_{2} \mathrm{O}_{3}$ выявлен эффект переключения под влиянием электрического поля из состояния с низким сопротивлением в состояние c BC.

3. Чувствительность к УФ-излучению в структурах с двухфазной пленкой оксида галлия появляется только после переключения в ВС-состояние.

\section{Конфликт интересов}

Авторы заявляют, что у них нет конфликта интересов.

\section{Список литературы}

[1] Lee S.-D., Ito Y., Kaneko K., Fujita S. // Jpn. J. Appl. Phys. 2015. V. 54. P. 030301. https://doi.org/10.7567/JJAP.54.030301

[2] Dakhel A.A. // Solid State Sci. 2013. V. 20. P. 54-58. https://doi.org/10.1016/j.solidstatesciences.2013.03.009

[3] Stepanov S.I., Nikolaev V.I., Bougrov V.E., Romanov A.E. // Rev. Adv. Mater. Sci. 2015. V. 44. P. 63-86.

[4] Cora I., Mezzadri F., Boschi F., Bosi M., Caplovicova M., Calestani G., Dodony I., Pecza B., Fornari R. // CrystEngComm. 2017. V. 19. P. 1509-1516. https://doi.org/10.1039/C7CE00123A

[5] Guo D., Qin X., Lv M., Shi H., Su Y., Yao G., Wang S., Li C., Li P., Tang W. // Electron. Mater. Lett. 2017. V. 13. P. 483-488. https://doi.org/10.1007/s13391-017-7072-y

[6] Qian L., Wu Z., Zhang Y., Lai P., Liu X., Li Y. // ACS Photon. 2017. V. 4. P. 2203-2211. https://doi.org/10.1021/acsphotonics.7b00359

[7] Roberts J.W., Chalker P.R., Ding B., Oliver R.A., Gibbon J.T., Jones L.A.H., Dhanak V.R., Phillips L.J., Major L.J., Massabuau F.C. // J. Cryst. Growth. 2019. V. 528. P. 125254. https://doi.org/10.1016/j.jcrysgro.2019.125254

[8] Xia X., Chen Y., Feng Q., Liang H., Tao P., Xu M., Du G. // Appl. Phys. Lett. 2016. V. 108. P. 202103. https://doi.org/10.1063/1.4950867

[9] Son H., Choi Y., Hwang J., Jeon D. // ECS J. Solid State Sci. Technol. 2019. V. 8. P. Q3024-Q3027. https://doi.org/10.1149/2.0051907jss

[10] Xu Y., Zhang C., Cheng Y., Li Z., Cheng Y., Feng Q., Chen D., Zhang J., Hao Y. // Materials. 2019. V. 12. P. 3670. https://doi.org/10.3390/ma12223670 
[11] Nikolaev V.I., Pechnikov A.I., Nikolaev V.V., Scheglov M.P., Chikiryaka A.V., Stepanov S.I., Medvedev O.S., Shapenkov S.V., Ubyivovk E.V., Vyvenko O.F. // J. Phys.: Conf. Ser. 2019. V. 1400. P. 055049. https://doi:10.1088/1742-6596/1400/5/055049

[12] Shapenkov S., Vyvenko O., Ubyivovk E., Medvedev O., Varygin G., Chikiryaka A., Pechnikov A., Scheglov M., Stepanov S., Nikolaev V. // Phys. Status Solidi A. First published: 14 February 2020. P. 1900892.

https://doi.org/10.1002/pssa.201900892

[13] Cho S.B., Mishra R. // Appl. Phys. Lett. 2018. V. 112. P. 162101. https://doi.org/10.1063/1.5019721

[14] Mezzadri F., Calestani G., Boschi F., Delmonte D., Bosi M., Fornari R. // Inorgan. Chem. 2016. V. 55. P. 12079-12084. https://doi.org/10.1021/acs.inorgchem.6b02244 